\title{
LA POLÍTICA SOCIAL Y LOS PROGRAMAS HACIA LA EXTREMA POBREZA DEL GOBIERNO MILITAR CHILENO
}

\author{
Pilar Vergara \\ Investigadora de la Facultad Latinoamericana \\ de Ciencias Sociales (FLACSO), Programa Santiago
}

Resum

L'article descriu els trets bàsics de la politica social portada a terme pel govern militar del general Pinochet. En primer lloc, l'autora es refereix a les actuacions concretes dedicades a combatre la pobresa a Xile in'analitza els resultats obtinguts. A continuació, realitza una sèrie de reflexions critiques sobre aquestes polítiques, tot mostrant els defectes d'una actuació governamental que canvia la logica del benestar per la lògica del mercat. Les recomanacions finals, fetes a manera d'orientació mirant un futur govern democràtic, reclamen una descentralització i participació més grans dels interessats en el control i la gestió de les polítiques socials.

Resumen

El artículo describe los rasgos básicos de la política social llevada a cabo por el gobierno militar del general Pinochet. En primer lugar, la autora muestra las actuaciones concretas destinadas a combatir la pobreza en Chile $y$ analiza los resultados obtenidos. A continuación, realiza una serie de reflexiones críticas en torno a tales políticas, mostrando los defectos de una actuación gubernamental que cambia la lógica del bienestar por la lógica del mercado. Las recomendaciones finales, hechas a modo de orientación para el futuro gobierno democrático, reclaman una mayor descentralización y participación de los interesados en el control y la gestión de las politicas sociales.

Abstract

The article describes the basic trends of social policies undertaken by the military government of general Pinochet. First of all, the author demonstrates that the concrete actions oriented to fighting the poverty in Chile and analyzes the results. After that she presents a list of critical reflections around these policies in order to show the defaults of a government action that changes welfare logic into a market one. The final recommendations, as an orientation for the future democratic government, suggest the decentralization and participation in the control and management of the social policies. 
«Papers»: Revista de Sociologia

\section{INTRODUCCIÓN}

Este trabajo pretende describir los rasgos fundamentales de la política social aplicada en Chile por el gobierno militar, analizar sus principales resultados, y reflexionar críticamente acerca de las perspectivas y desafíos que plantean al quehacer social del estado. En él se pone especial énfasis en el examen de los programas focalizados en la extrema pobreza. Esta segunda línea de acción estatal en materia social, pese a constituir una experiencia novedosa e innovadora, ha sido hasta ahora objeto de muy escasos estudios sistemáticos, por lo que su análisis nos parece de especial significación y relevancia. Sólo muy brevemente se analizan las otras dimensiones de la acción pública en este ámbito.

Pero el interés por estos programas no es sólo académico. Con todas sus deficiencias y limitaciones, el intento de canalizar una mayor proporción del gasto social hacia los grupos más postergados, que tradicionalmente habían quedado al margen de los beneficios estatales, confiere a estas experiencias un carácter inédito y original, no sólo en Chile sino también en todo el concierto latinoamericano, de cuyos logros, éxitos y fracasos es posible extraer valiosas lecciones para el diseño de políticas alternativas de erradicación de la pobreza, que puedan ser aplicadas en el futuro democrático que se avecina.

El régimen autoritario que se instala en el poder en 1973 parte de un diagnóstico que no es del todo erróneo: las políticas sociales en el pasado se habían mostrado sistemáticamente incapaces de llegar con sus beneficios a los segmentos más pobres de la población, relegándolos así a una situación de pobreza y marginalidad económica y social. Los principales beneficiarios del enorme esfuerzo que desplegaba el estado a través de su acción social habían sido los grupos medios y los trabajadores asalariados vinculados a las actividades más dinámicas de la economía, sin que sus efectos se hicieran sentir de manera significativa en los estratos inferiores, mayoritariamente conformados por personas desocupadas o que carecen de un empleo estable, trabajadores por cuenta propia y asalariados del sector informal, situaciones todas que hacían imposible llegar hasta ellos con los instrumentos distributivos tradicionales.

Desde sus inicios, el gobierno actual sostiene que el objetivo fundamental de su política social es la erradicación de la extrema pobreza, atribuyéndole en cambio al estado una extrema ineficiencia en las funciones distributivas, las cuales habrían resultado, no un alivio, sino una acentuación de las desigualdades. Los progresos en la distribución del ingreso no pueden prevenir de la intervención estatal, sino del crecimiento de la economía que permitirían las fuerzas del mercado si se las deja operar libremente, y del «rebalse» de 
los frutos del desarrollo hacia las actividades y grupos sociales más rezagados.

En suma, el estado debe abandonar el papel igualizador que desempeñó en el pasado, que buscaba compensar las desigualdades reales y crear canales de movilidad social, para limitar su acción social a la puesta en marcha de programas selectivos, dirigidos específicamente hacia aquellos segmentos de la población que no están en condiciones de satisfacer sus necesidades más imprescindibles, evitando «filtraciones» indebidas del gasto social hacia otros grupos menos necesitados.

\section{LA NUEVA ESTRATEGIA DE DESARROLLO SOCIAL}

\section{FUNDAMENTOS IDEOLÓGICOS}

El núcleo central de la ideología que ha sustentado la acción pública en los más diversos ámbitos - y, en particular, las políticas de erradicación de la pobreza crítica - es el denominado principio de la subsidiariedad del estado. De acuerdo con este principio, el aparato estatal debe abstenerse de toda forma de intervención, y asumir únicamente aquellas responsabilidades que los particulares o las sociedades intermedias no están en condiciones de desempeñar adecuadamente.

La existencia de un estado subsidiario es concebida como condición insoslayable de la plena realización de los dos valores sociales considerados fundamentales: la libertad individual y la igualdad de oportunidades (Vergara, 1985). La libertad individual no es precisamente la libertad ciudadana; en el ámbito social, es simplemente el derecho de cada persona de elegir en el mercado, según sus preferencias, los bienes y servicios básicos que requiere, sin ser coartada por el estado o cualquier otro agente externo, ya sean grupos de poder, burocracias estatales o partidos políticos.

La igualdad de oportunidades, por su parte, es también definida en oposición al intervencionismo estatal: se alcanzaría sólo cuando es el mercado el que regula el suministro y acceso a las prestaciones sociales. En el mercado todos son formalmente iguales y no es posible discriminar entre los individuos en función de sus atributos personales o recursos de poder, por lo que sólo en él las oportunidades se distribuirían «igualitariamente». En cambio, la idea de justicia social que inspiraba las políticas sociales del pasado, no haría más que agudizar las injusticias y las desigualdades, al buscar la igualdad en los resultados para diferentes esfuerzos.

No obstante, para que todos los miembros de la sociedad disfruten de una efectiva libertad e igualdad de oportunidades, se requiere que toda la 
población esté en condiciones de satisfacer, a un nivel siquiera mínimo, sus necesidades básicas, tales como la alimentación, la salud, la vivienda, etc. De otro modo, las personas afectadas se encuentran inhabilitadas para participar en el mercado, por lo que no pueden ejercer su libertad ni impera para ellas una auténtica igualdad de oportunidades, las que son incompatibles con la extrema pobreza.

De ahí que, en el caso de que haya grupos afectados por situaciones de miseria aguda, corresponde al estado, en cumplimiento de su rol subsidiario, intervenir activamente a fin de lograr la definitiva erradicación del fenómeno, asegurando a todos acceso a los bienes y servicios esenciales que les permitan superar sus carencias más agudas. Sólo una vez alcanzado este objetivo, se evitaría la generación de desigualdades que no sean las que "provengan de Dios o del mérito» (ODEPLAN, Informe social 1983). A partir de ese momento, las desigualdades que subsistan dependerán sólo de los atributos personales, de la capacidad y el esfuerzo de cada cual.

Se desprende de lo anterior que el respeto del postulado de la subsidiariedad en la política social exige minimizar el tamaño y las funciones sociales del estado, y estructurar una nueva institucionalidad social sometida por completo a las leyes del mercado competitivo.

\section{CON'IENIDO Y ORIENTACIONES DE I.A NUEVA POLÍTICA SOCIAL}

Estas nuevas concepciones sobre la función social del estado se materializan en un conjunto de medidas que promueven la jibarización y el repliegue sistemático del aparato público en este campo, a través de una drástica reducción del gasto público destinado a fines sociales ${ }^{1}$, y del traspaso a la iniciativa privada de la tarea de proveer los bienes y servicios básicos, dejando que el mercado se encargue de regular el acceso a esas prestaciones.

Para cumplir con esos objetivos, una vez consolidado el modelo económico de libre mercado, se da impulso a un ambicioso plan de reformas - las denominadas «modernizaciones» sociales-, que prolongan hacia el área social los principios mercantiles imperantes en la economía. A través de ellas, se promueve la creación de un sistema privado de servicios sociales de alto nivel para los sectores de más altos ingresos, en el cual las atenciones que

1. Los gastos sociales caen en forma drástica, particularmente en el bienio 19751976, a raíz de la puesta en marcha de un plan de estabilización extremadamente ortodoxo: el denominado "plan de shock». A partir de 1977, el gasto social inicia una lenta pero sostenida recuperación que le permitió alcanzar a principios de 1980 los niveles reales de comienzos de la década anterior. Sin cmbargo, en términos per cápita, se mantiene todavía una brecha apreciable. 
recibe el usuario corresponden a la magnitud de su aporte económico. Se trata de que todos los que no son pobres, es decir, quienes tienen poder adquisitivo suficiente, financien con sus propios medios las atenciones sociales que antes recibían del estado.

La acción asistencial del estado debe limitarse, entonces, a la materialización de programas dirigidos hacia los hogares que se debaten en la pobreza aguda, asegurándoles acceso, al margen del mercado, a los bienes y servicios indispensables para suplir sus carencias básicas. Con ese propósito, se ponen en marcha un conjunto de programas - que conforman la denominada red social del gobierno- que procuran focalizar la ayuda en los sectores más desposeídos, distribuyendo subsidios de acuerdo a criterios de necesidad y no de capacidad de pago.

La acción social del estado sufre así una profunda transformación, cuya radicalidad no habían conocido esfuerzos anteriores de este tipo, ni siquiera durante el gobierno de la Unidad Popular. En efecto, con creciente nitidez se ha ido configurando una dualización de la acción pública en este campo: privatización y libre mercado para algunos, y asistencialismo y dependencia de subsidios estatales destinados a asegurar la subsistencia — no así la distribución del ingreso o la movilidad social- para otros. Esa progresiva dualización de la política social, en la cual parece revelarse lo esencial de la política pública del régimen militar chileno, ha desencadenado profundos cambios en la estructura social del país, que han contribuido a profundizar la fragmentación de la sociedad chilena provocada por la imposición del sistema económico librecambista.

\section{LAS «MODERNIZACIONES» SOCIALES}

A través de este conjunto de reformas modernizantes - las más radicales que se emprenden en el ámbito social- se avanza en forma acelerada hacia la privatización de los servicios sociales, transfiriendo al mercado la principal responsabilidad en la satisfacción de las necesidades básicas de la población ${ }^{2}$.

En el campo de la salud, la orientación privatizadora se expresó en una profunda reestructuración de la salud estatal. Por un lado, se introdujeron criterios de mercado en la administración y financiamiento de los servicios

2. Las modernizaciones combinan la privatización de las funciones sociales del estado con medidas destinadas a minimizar el poder de los sindicatos, de los gremios y colegios profesionales, respondiendo con ello al mismo objetivo de instaurar relaciones sociales regidas exclusivamente por las leyes del mercado competitivo (Vergara, 1985). 
públicos, traspasando al usuario el costo de las prestaciones, y estableciendo una estrecha relación entre la contribución económica que éste hace al sistema y la retribución que recibe de él en términos de la cantidad y calidad de las prestaciones a que tiene acceso. Junto a ello, se promovió el desarrollo de la medicina privada al autorizarse la creación de las Instituciones de Salud Previsional (ISAPRES). Éstas son entidades privadas con fines de lucro que ofrecen servicios médicos a cambio de la contribución obligatoria para atenciones de salud de los trabajadores que se acogen a ellas. En éstas, los beneficios médicos que recibe cada afiliado son proporcionales a su aporte económico. La medida significó un traspaso de cuantiosos recursos públicos a la medicina privada y una simultánea disminución de los aportes recibidos por la salud estatal.

En el ámbito educacional, se inició a partir de 1979 una profunda reestructuración del sistema: se traspasó la gestión de los establecimientos fiscales a las municipalidades, que pueden a su vez transferir su administración a entidades privadas. Junto a ello, se modificó el sistema de financiamiento de la educación, comprometiéndose el estado a entregar a las escuelas, tanto públicas como particulares gratuitas, una subvención por cada alumno que asiste a clases. A través de este mecanismo se buscaba estimular la expansión de la enseñanza privada y promover una administración de los establecimientos públicos orientada por criterios de rentabilidad privada.

La política habitacional apunta también a entregar al sector privado la tarea de construir viviendas sociales, correspondiendo a las instituciones públicas atender las necesidades habitacionales de los hogares que no cuentan con ingresos suficientes para procurarse, con sus propios medios, una vivienda mínima. Con ese propósito, se pusieron en marcha diferentes líneas de subsidio habitacional, que se otorgan directamente al beneficiario para que éste haga uso de él adquiriendo en el mercado una vivienda propia ${ }^{3}$.

En el ámbito laboral, se dictó en 1979 el denominado Plan Laboral. Éste restableció la negociación colectiva - aunque dentro de límites muy estrechos-, pero dispuso que ésta sólo puede llevarse a cabo sin la intervención del gobierno como árbitro y mediador, ni de las federaciones y confederaciones de trabajadores, como había ocurrido en el pasado. Debe quedar, además, restringida a nivel de empresas individuales y referida únicamente a los trabajadores del sector privado. Por otro lado, se autoriza la formación de más de una sindicato por empresa y se concede el derecho al lock out o cierre temporal de empresas a los empleadores ${ }^{4}$.

3. Véase, al respecto, Arellano (1975); Haramoto (1983); MacDonnald (1983); Vergara (1989); Puga (1986).

4. Vergara (1985). 
Finalmente, en 1980 se da un paso trascendental en el proceso de privatización de las funciones sociales del Estado: la reforma previsional. Ésta, que afecta sólo al régimen de pensiones, sustituyó el antiguo sistema de reparto por uno de capitalización individual, que es administrado por instituciones privadas: las Administradoras de Fondos de Pensiones (AFP). En ellas, los beneficios previsionales que reciben los trabajadores al término de su vida productiva son equivalentes a los aportes realizados durante sus años de actividad. El traslado de trabajadores desde el antiguo régimen de reparto hacia el nuevo sistema significó un traspaso tan considerable de fondos públicos a dichas instituciones, que éstas llegaron rápidamente a concentrar una cuota significativa del patrimonio y del poder económico (Arellano, 1985).

\section{LOS PROGRAMAS SOCIALES HACIA LA EXTREMA POBREZA}

De acuerdo con el enfoque prevaleciente acerca de las causas de la extrema pobreza y de la responsabilidad del Estado frente a ella, ni las estrategias globales ni los programas concretos diseñados para combatirla consultan modificaciones del orden económico y social imperante. Tampoco contemplan medidas tendientes a promover una distribución más equitativa del ingreso si ese objetivo va más allá de asegurar a todos un umbral mínimo de bienestar. La superación de las situaciones más graves de pobreza sólo puede provenir de la aplicación de programas selectivos que, a diferencia de las medidas redistributivas tradicionales, de cobertura universal $y$, en consecuencia, de impacto poco discriminatorio, procuran atender las necesidades esenciales de aquellos segmentos de la población que se debaten en la indigencia.

\section{Los pobres: tamaño de la población-objetivo}

La implementación de modalidades selectivas de acción social, al igual que cualquier evaluación que se haga del cumplimiento de sus metas y objetivos, requiere cuantificar, aunque sea en términos globales y aproximados, el tamaño de la población-objetivo que debiera ser atendida.

¿Cuánta gente vive en condiciones de extrema pobreza? Pese a tratarse de un problema de reconocida gravedad, que afecta a un elevado porcentaje de la población chilena, nunca se ha dado a conocer información oficial acerca de la real dimensión del fenómeno, ni del número de familias ubicadas en los índices inferiores de la Ficha CAS, lo que constituye una de las omisiones más notables y paradójicas de las actuales políticas de ataque a la pobreza. 
Sin embargo, existen estudios que aportan estimaciones útiles acerca de la extensión que alcanza el fenómeno ${ }^{5}$. Definiendo como pobres a aquellos hogares que perciben un ingreso familiar inferior al requerido para adquirir una canasta mínima de subsistencia. Dichos estudios permiten concluir que, alrededor de 1985, el número de hogares sumidos en la indigencia se aproximaba a los $800 \mathrm{mil}$, lo que representa aproximadamente 4 millones de personas, esto es, una tercera parte de la población total del país ${ }^{6}$.

\section{Mecanismos de identificación de beneficiarios}

La aplicación y manejo efectivo de programas de este tipo exige contar con un instrumento idóneo de identificación y priorización de sus beneficiarios potenciales, que asegure que los subsidios se focalizan efectivamente en los más necesitados.

Para tal efecto, se diseñó un instrumento que permite identificar los hogares que requieren atención prioritaria, conocido como Ficha CAS. Ésta, que fue construida únicamente sobre la base de procedimientos técnico-estadísticos, consiste en un cuestionario que registra los principales antecedentes socio-económicos del grupo familiar (características de la vivienda, actividad y nivel de escolaridad del jefe del hogar y su cónyuge, entre otras) y también información individualizada sobre cada uno de sus miembros (edad, sexo, parentesco con el jefe del hogar, nivel educacional, etcétera), asignando a cada una de estas variables una determinada ponderación. La encuesta no contempla información sobre los ingresos del hogar. El resultado de este conjunto de antecedentes se expresa en una puntuación global (Índice CAS), que estratifica a la población en cinco niveles, según la gravedad de sus carencias: el 1 corresponde a la situación más crítica y el 5 a la de mayor bienestar relativo. Son beneficiarios potenciales (población-objetivo) de los subsidios hacia la pobreza crítica, las personas que queden estratificadas en alguno de los tres índices inferiores de la Ficha.

5. Véase, entre otros, Rodríguez (1985); Torche (1985; 1988); García (1986); Vergara (1989). La mayor parte de estas investigaciones se basan en el valor de la canasta básica de subsistencia calculada por CEPAL (Altimir, 1979).

6. En este trabajo hemos considerado en extrema pobreza a los hogares situados en los tres deciles inferiores de la estructura distributiva, cuyo ingreso familiar per cápita es, según los resultados de la encuesta CASEN, inferior al valor de la canasta básica de subsistencia calculado por CEPAL.

Dados los supuestos conservadores utilizados en el cálculo, esta cifra representa el tamaño mínimo que puede alcanzar la población-objetivo de los programas hacia la pobreza crítica, siendo muy probable que dicho trabajo subestime su real magnitud. 
La política social y los programas hacia la extrema pobreza

Algunos programas especificos

En las páginas que siguen se describen someramente las principales características y resultados de algunos de los programas hacia la extrema pobreza más importantes puestos en marcha por el régimen militar chileno.

\section{Previsión social}

En esta área, se crearon dos nuevos programas: el Subsidio Único Familiar (SUF) y las Pensiones Asistenciales (PASIS), que extendieron los beneficios provisionales a sectores tradicionalmente desprotegidos.

\section{Subsidio Único Familiar (SUF)}

Su instauración en 1981 significó extender el pago de la asignación familiar a los menores de 15 años pertenecientes a familias de extrema pobreza y cuyos padres carecen de previsión ${ }^{7}$. Posteriormente, el goce de este beneficio se hizo extensivo a las mujeres embarazadas de la misma condición.

El subsidio tiene un monto mensual equivalente a la asignación familiar que se otorga a la población afiliada a alguna institución previsional (aproximadamente 5 dólares). Los beneficiarios tienen además acceso gratuito a todas las prestaciones que entrega el servicio de salud estatal -el Sistema Nacional de Servicios de Salud (SNSS) - , y para obtener el beneficio, deben comprobar su participación en los programas de atención primaria maternoinfantil establecidos por el Ministerio de Salud.

Los beneficios concedidos por este programa se incrementan en forma acelerada: en 1982 el número de SUF otorgados mensualmente es nueve veces superior al correspondiente a los primeros cuatro meses de vigencia del programa, y al año siguiente, se duplican los niveles del año anterior. A partir de 1985, en cambio, los beneficios concedidos se estancan en torno al millón de subsidios, para descender en 1988 (Cuadro 1, p. 36). Ello obedece a que ese año se fijó un tope máximo a la cantidad de subsidios que podían ser concedidos mensualmente, independientemente de cuál fuera el número de postulantes que acreditaran el cumplimiento de los requisitos que establece la ley para tener derecho al beneficio.

Se calcula que en 1985 este subsidio alcanzó a un 30\% de la población total menor de 15 años, coeficiente que se eleva al 70\% si se considera como

7. Inicialmente, el subsidio era otorgado sólo a los menores de 6 años. Con posterioridad, se extendió el derecho a optar por este beneficio a los menores de 8 años y, a partir de 1982, se elevó el límite de edad a 15 años. 
grupo-objetivo sólo a los niños de hogares en extrema pobreza. En cuanto a su selectividad, diversas estimaciones coinciden en señalar que ese año dos tercios del gasto efectuado por el Fisco en este subsidio se focalizó en el $30 \%$ de los hogares de menores ingresos, lo que indica una eficacia selectiva bastante elevada ${ }^{8}$.

\section{CUAdro 1}

Subsidios previsionales dirigidos hacia la extrema pobreza

1975-1988

\begin{tabular}{|c|c|c|c|c|c|c|c|}
\hline \multirow[b]{2}{*}{ Año } & \multicolumn{3}{|c|}{ Subsidio unico familiar } & \multicolumn{4}{|c|}{ Pensiones asistenciales } \\
\hline & $\begin{array}{l}\text { Subsidios cance- } \\
\text { lados (promedios } \\
\text { mensuales)" }\end{array}$ & $\begin{array}{l}\text { Variación (\%) } \\
\text { respecto al año } \\
\text { anterior }\end{array}$ & $\begin{array}{l}\text { Monto unitario } \\
\text { (\$de 1985) }\end{array}$ & $\begin{array}{l}\text { Pensiones otor- } \\
\text { gadas (promedios } \\
\text { mensuales) }\end{array}$ & $\begin{array}{l}\text { Variación (\%) } \\
\text { respecto al año } \\
\text { anterior }\end{array}$ & $\begin{array}{l}\text { Como \% total } \\
\text { pensiones paga- } \\
\text { das por Seg. Soc. }\end{array}$ & $\begin{array}{l}\text { Monto unitario } \\
\text { (\$de 1985) }\end{array}$ \\
\hline 1975 & - & - & - & 27.784 & - & - & - \\
\hline 1976 & - & - & - & 38.959 & 40.0 & $s / i$ & - \\
\hline 1977 & - & - & - & 62.245 & 59.7 & 7.1 & $s / i$ \\
\hline 1978 & - & - & - & 91.027 & 46.2 & 9.3 & $s / i$ \\
\hline 1979 & - & - & - & 112.338 & 23.4 & 11.0 & $s / i$ \\
\hline 1980 & - & - & - & 130.982 & 16.6 & 12.2 & 3.052 \\
\hline 1981 & 25.192 & - & 818 & 155.499 & 18.7 & 13.8 & 3.973 \\
\hline 1982 & $268.478^{* * n}$ & - & 802 & 183.217 & 17.8 & 15.4 & 3.770 \\
\hline 1983 & 623.755 & 130.0 & 646 & 228.718 & 24.8 & 18.4 & 3.588 \\
\hline 1984 & 790.323 & 30.0 & 634 & 278.447 & 21.7 & 20.6 & 4.028 \\
\hline 1985 & 1.040 .900 & 30.0 & 600 & 320.789 & 15.2 & 23.8 & 3.267 \\
\hline 1986 & 1.044 .383 & 0.3 & 502 & 324.115 & 1.0 & 23.8 & 3.180 \\
\hline 1987 & 1.024 .624 & -2.0 & 419 & 321.567 & -0.8 & 23.9 & 2.848 \\
\hline 1988 & 859.951 & -16.1 & 419 & 308.203 & -4.2 & $s / i$ & $s / i$ \\
\hline
\end{tabular}

FUENTES: SUF : Servicio de Seguro Social y Superintendencia de Seguridad Social, Seguridad Social, varios años.

PASIS : Superintendencia de Seguridad Social, Boletines Estadisticos y antecedentes no publicados proporcionados por el Departamento de Estadísticas, Dirección Actuarial.

* Incluye subsidios otorgados a niños y embarazadas.

* El programa fue creado a comienzos de 1981. La cifra de ese año considera sólo a niños, que eran en esa fecha los únicos beneficiarios potenciales de este subsidio.

8. Estimaciones realizadas sobre la base de los resultados de la encuesta CASEN. Dicho estudio fue realizado conjuntamente por ODEPLAN y el Departamento de Economía de la Universidad de Chile en noviembre de 1985, en una muestra de 20 mil personas de las 13 regiones del país. Tuvo por objetivo medir el acceso que los hogares de diferente nivel de ingreso tenían a los subsidios estatales. 
La política social y los programas hacia la extrema pobreza

\section{Pensiones Asistenciales (PASIS)}

Creado en 1975, este programa extendió el régimen de pensiones asistenciales a la población mayor de 65 años y a los inválidos mayores de 18 , carentes de recursos, que se encuentran marginados de la seguridad social. Para tener derecho al subsidio, los postulantes deben comprobar formalmente que, además de carecer de previsión, no perciben ingresos propios, y que la renta per cápita de su grupo familiar no supera el 50\% del valor de la pensión mínima.

El beneficio consiste en una pensión mensual cuyo monto equivale a un tercio de la pensión mínima. En 1985, las PASIS tenían un valor equivalente a la mitad del ingreso mínimo legal (aproximadamente 20 dólares mensuales).

Durante los diez primeros años de vigencia del programa, la población atendida crece en forma acelerada: el número de beneficios concedidos mensualmente aumenta a tasas superiores en promedio al $25 \%$ anual, para declinar a comienzos de 1987, cuando los beneficios cancelados se estancan en los niveles registrados durante 1985 (Cuadro 1). Pese a ello, las PASIS representaron en ese año casi la cuarta parte del total de pensiones canceladas por las instituciones previsionales. El brusco estancamiento de los beneficios concedidos por este programa es atribuible a que, al igual que en el caso del SUF, ese año fue congelado el número de PASIS que pueden ser otorgadas mensualmente, no permitiéndose desde esa fecha conceder nuevas pensiones, salvo para llenar las vacantes que cada mes quedarán libres por fallecimiento del beneficiario, o por haber éste dejado de cumplir con los requisitos que exige la ley.

A pesar del dinámico crecimiento que experimenta esta prestación, su cobertura sigue siendo insuficiente para abarcar a todos sus beneficiarios potenciales. Como indicador, aunque muy indirecto, puede utilizarse el porcentaje de PASIS distribuidas entre la fuerza de trabajo no protegida por la seguridad social. En 1986, el mencionado coeficiente oscilaba en torno al $15 \%$. En cambio, las pensiones canceladas por los institutos previsionales respecto del total de imponentes activos se aproximaba al 50\%.

Se estima que en 1985 el $53 \%$ del aporte fiscal destinado al pago de estas pensiones favorecía al quintil más pobre de la población, lo que, considerando la naturaleza del programa, denota una insuficiente selectividad.

\section{Programa Nacional de Alimentación Complementaria (PNAC)}

Creado en 1954, este programa consiste en la distribución gratuita de alimentos, básicamente leche y mezclas proteicas, a los menores de 6 años, embarazadas y nodrizas beneficiarias del Sistema Nacional de Servicios de Salud (SNSS), sin discriminación. 
«Papers»: Revista de Sociologia

Pese a tener cobertura universal, el PNAC puede ser incluido entre los programas contra la pobreza, debido a que durante los últimos años ha privilegiado decididamente a los grupos más pobres o nutricionalmente más vulnerables. Si bien los esfuerzos por mejorar su selectividad se habían iniciado con bastante anterioridad, se acentúan a partir de 1973, con la puesta en marcha de dos subprogramas focalizados en los grupos de riesgo biomédico (desnutridos o en riesgo de desnutrir) y socio-económico (pobreza crítica), hacia los cuales se canalizó el grueso de la ayuda. En 1985, este último subprograma fue suprimido, con lo cual la atención del PNAC pasó a quedar concentrada en quienes presentan ya síntomas evidentes de desnutrición. A estos últimos se les entrega, además de los productos del programa básico, un refuerzo alimentario con un mayor aporte energético y proteico.

En la actualidad, el beneficio que entrega este programa consiste en cinco raciones diferentes de alimentos, cuya composición, cantidad y aporte energético varía conforme a la edad, el estado fisiológico y la situación nutricional de los beneficiarios. Sin entrar en un examen pormenorizado de los productos distribuidos, es importante consignar que, tanto la cantidad de alimentos proporcionados por el programa básico como la calidad y aporte nutricional de éstos, se ha deteriorado progresivamente, como resultado, tanto de los recortes presupuestarios que ha sufrido el programa, como de la canalización de una proporción creciente de los recursos hacia el subprograma focalizado. Esto ha erosionado severamente la efectividad e impacto de esta intervención, al desincentivar la participación en el programa de los beneficiarios que no presenten un estado nutricional comprometido (García, 1983; Atalah y otros, 1986; Ffrench-Davis y Raczynski, 1987; Vergara, 1989).

La cantidad de alimentos distribuidos por el PNAC focalizado en los grupos de riesgo, en cambio, se incrementa en forma sostenida, pese a que éstos no representan más que la cuarta parte del total de beneficiarios de esta intervención.

Consecuencia directa de lo anterior ha sido el drástico deterioro de la cobertura del programa, tanto respecto de su población-objetivo como de los requerimientos energéticos de todas las categorías de beneficiarios (con la excepción, obviamente, de los grupos de riesgo). Además, después de haber constituido en esencia una intervención nutricional preventiva, el PNAC tiende a convertirse progresivamente en un programa eminentemente curativo, con lo cual se han desvirtuado los objetivos para los cuales éste fue creado, y se han arriesgado sus principales logros.

La selectividad del PNAC viene dada por dos mecanismos. Uno es indirecto: la exigencia de asistir regularmente a los controles de salud en los establecimientos del SNSS para poder recibir los alimentos, lo que lleva a que parte considerable de los sectores de mayores recursos, que pueden recurrir a 
la medicina privada, se automarginen del programa. El otro es directo, y está constituido por el subprograma focalizado. Gracias a la interacción de ambos mecanismos, esta intervención ha alcanzado una selectividad bastante elevada: a fines de 1985 , el $30 \%$ de los hogares de menores ingresos captaba la mitad de los recursos del programa.

\section{Educación preescolar}

Existen tres programas que dan asistencia a los preescolares pertenecientes a hogares pobres: los Jardines de la Junta Nacional de Jardines Infantiles (JUNJI); los Centros Abiertos (CA); y la Educación pre-básica dependiente del Ministerio de Educación. Aquí nos referiremos solamente a los dos primeros, que son los únicos que focalizan su atención en los preescolares afectados por la extrema pobreza.

\section{Jardines Infantiles de la JUNJI}

Este programa tiene como objetivo proporcionar atención gratuita e integral a niños menores de 6 años provenientes de hogares en extrema pobreza o con problemas nutricionales.

Hasta hace algún tiempo, el único criterio utilizado para la selección de beneficiarios era el Índice CAS en el cual se encuentra estratificado el menor. Posteriormente, se añadió el estado nutricional del párvulo, dándose con frecuencia prioridad a los menores en situación de riesgo, aun cuando no pertenezcan a hogares clasificados en los niveles inferiores de la Ficha, con ello la atención ha tendido progresivamente a privilegiar el tratamiento del daño nutricional por encima de los aspectos psicopedagógicos, que habían constituido el propósito fundamental del quehacer de la JUNJI.

Los menores son atendidos en jornadas diarias de 8 horas y reciben un servicio que comprende asistencia psicopedagógica, médico-dental y alimentario-nutricional. Esta última consiste en tres raciones diarias, con un aporte nutricional que cubre aproximadamente el $75 \%$ de los requerimientos alimentarios de los párvulos. A los que presentan algún grado de desnutrición, se les proporciona un suplemento calórico especial, con lo cual se cubre el total de sus necesidades.

La atención integral que proporcionan los Jardines representaba a fines de 1985 un subsidio equivalente a aproximadamente cuatro mil pesos mensuales (23 dólares), lo que para una familia en extrema pobreza equivalía ese año a un $44 \%$ de su renta mensual per cápita (Haindl y Weber, 1986). Esta cifra pone de relieve la significación que el beneficio alcanza en el consumo de los niños favorecidos y como fuente de ingresos complementarios para la familia. 
«Papers»: Revista de Sociologia

\section{CUADRO 2}

Atención preescolar: Matrícula de la JUNJI (programa regular) y de centros abiertos, 1973-1987

\begin{tabular}{|c|c|c|c|c|}
\hline \multirow[b]{2}{*}{$A \tilde{n} 0$} & \multicolumn{2}{|c|}{$J U N J I$} & \multicolumn{2}{|c|}{ Centros abiertos } \\
\hline & $\begin{array}{c}\text { Matricula } \\
\text { programa regular }\end{array}$ & $\begin{array}{l}(\%) \text {. variación } \\
\text { respecto año anterior }\end{array}$ & Matrícula & $\begin{array}{l}\text { (\%) variación } \\
\text { respecto año anterior }\end{array}$ \\
\hline 1973 & 10.085 & - & - & - \\
\hline 1974 & 16.199 & 60.6 & - & - \\
\hline 1975 & 31.743 & 96.0 & - & - \\
\hline 1976 & 33.041 & 4.1 & - & - \\
\hline 1977 & 39.588 & 19.8 & - & - \\
\hline 1978 & 39.948 & 0.9 & - & - \\
\hline 1979 & 46.987 & 17.6 & 19.789 & - \\
\hline 1980 & 47.690 & 1.5 & 25.766 & 30.2 \\
\hline 1981 & 47.614 & -0.2 & 28.483 & 10.6 \\
\hline 1982 & 47.529 & -0.2 & 32.086 & 12.7 \\
\hline 1983 & 45.459 & -4.4 & 36.099 & 12.5 \\
\hline 1984 & 45.629 & 0.4 & 43.410 & 20.03 \\
\hline 1985 & 53.578 & 17.4 & 47.000 & 8.3 \\
\hline 1986 & 55.909 & 4.4 & 43.507 & 7.4 \\
\hline 1987 & 56.535 & 1.1 & 45.477 & 4.5 \\
\hline
\end{tabular}

La matrícula de los Jardines se elevó de diez mil niños en 1973 a cincuenta y seis mil quinientos en 1987, lo que significó aumentar los niveles de atención en 5,6 veces en esos 14 años (Cuadro 2).

Desde 1981, la JUNJI comenzó a desarrollar cuatro modalidades no tradicionales de atención - algunas sólo con carácter de proyecto piloto-que reducen el tiempo de permanencia diaria de los menores en el centro asistencial, e integran a la familia, y en particular a la madre, al proceso educativo de los párvulos ${ }^{9}$. Esto les ha permitido abaratar sustancialmente los costos de la atención en comparación con el programa regular, sin sacrificar su efectividad, sino incluso mejorándola en algunos aspectos (JUNJI, 1986).

Estas nuevas modalidades de atención atendieron en 1986 a 10 mil menores, lo que permitió elevar ese año la matrícula total de la JUNJI en un $15 \%$.

9. De estas nuevas modalidades de atención, algunas privilegian la estimulación socio-emocional y el desarrollo psicomotor y del lenguaje de los párvulos, en tanto que otras se encuentran orientadas fundamentalmente hacia niños que presentan un estado nutricional alterado. 


\section{Centros abiertos (CA)}

Este programa, que es administrado por la Fundación Nacional de Ayuda a la Comunidad (FUNDACO), proporciona cuidado diurno y asistencia alimentaria - que cubre el $80 \%$ de los requerimientos calórico-proteicos diarios de sus beneficiarios - a niños entre 2 y 5 años provenientes de familias en extrema pobreza, y preferencialmente a desnutridos. Se les brinda, asimismo, educación orientada a la formación de hábitos, recreación, control sanitario y atención médica en los consultorios del SNSS.

A diferencia de los Jardines de la JUNJI, estos centros privilegian las necesidades asistenciales de los niños por encima de la atención psicopedagógica, pues no cuentan con suficiente personal calificado para tal propósito: un contingente significativo del personal que atiende los CA proviene de organizaciones del voluntariado femenino y de los programas de empleo de emergencia.

En 1979 había 243 establecimientos que atendían aproximadamente a veinte mil menores. Ocho años después, el número de CA se había más que duplicado y los niños atendidos superaban los 45 mil.

La JUNJI y los CA en conjunto atendieron en 1987 a algo más de cien mil párvulos, lo que representa apenas un $9 \%$ de la población menor de seis años. Si se considera sólo a los menores de ese grupo de edad provenientes de hogares en extrema pobreza, la cobertura de estos centros asistenciales habría alcanzado al $14 \%$ de sus beneficiarios potenciales, todo esto en el supuesto que no hay filtraciones de los beneficios hacia otros niños menos necesitados. En consecuencia, el déficit de atención de los preescolares pobres se aproximaba en esa fecha el $86 \%$.

La información disponible no permite establecer el grado de selectividad que han alcanzado estos programas. No obstante, entrevistas realizadas a docentes, educadoras de párvulos y supervisoras de la JUNJI revelan que los niños que asisten a estos centros provienen prácticamente en su totalidad de hogares extremadamente pobres, y que un porcentaje muy elevado de ellos sufre algún grado de desnutrición ${ }^{10}$.

10. Si en el cálculo de la cobertura de la atención se incluye a los menores matriculados en establecimientos municipales y particulares subvencionados dependientes del Ministerio de Educación - que en sentido estricto no constituyen programas focalizados en la pobreza crítica, pero atienden prioritariamente a niños provenientes de familias de bajos ingresos-, resulta que la educación pre-básica gratuita alcanzó en 1987 a un $19 \%$ de la población menor de 6 años. 
«Papers»: Revista de Sociologia

\section{CUADRO 3}

Programa de alimentación escolar (PAE): raciones diarias, 1973-1988*

\begin{tabular}{lcccccc}
\hline & $\begin{array}{c}\text { Desayunos/ } \\
\text { Indices } \\
\text { (miles) }\end{array}$ & $\begin{array}{c}\text { (\%) Variación } \\
\text { respecto alaño } \\
\text { anterior }\end{array}$ & $\begin{array}{c}\text { Almuerzos } \\
\text { (miles) }\end{array}$ & $\begin{array}{c}\text { (\%) Variación } \\
\text { respecto al año } \\
\text { anterior }\end{array}$ & $\begin{array}{c}\text { Raciones comple- } \\
\text { tas equivalentes } \\
\text { (miles) }\end{array}$ & $\begin{array}{c}\text { (\%) Variación } \\
\text { respecto al año } \\
\text { anterior }\end{array}$ \\
\hline 1973 & $1,443.6$ & - & 614.8 & - & 867.5 & - \\
1974 & $1,338.6$ & -7.4 & 663.2 & -1.7 & 882.1 & 1.7 \\
1975 & 745.7 & -44.3 & 593.6 & -10.5 & 631.6 & -28.4 \\
1976 & 769.8 & 3.2 & 361.0 & -39.2 & 463.2 & -26.7 \\
1977 & $1,055.2$ & 37.1 & 296.3 & -17.9 & 486.0 & 4.9 \\
1978 & $1,054.6$ & -0.1 & 307.6 & 3.8 & 494.2 & 1.7 \\
1979 & 759.4 & -28.0 & 294.6 & -4.2 & 410.8 & -16.9 \\
1980 & 759.9 & 0.1 & 295.0 & 0.1 & 411.3 & 0.1 \\
1981 & 759.1 & -0.1 & 295.1 & 0.03 & 411.1 & -0.1 \\
1982 & 689.7 & -9.1 & 295.3 & 0.1 & 393.9 & -4.2 \\
1983 & 673.8 & -2.3 & 323.2 & 9.5 & 410.9 & 4.3 \\
1984 & 674.6 & 0.1 & 424.9 & 131.5 & 487.3 & 18.6 \\
1985 & 691.0 & 2.4 & 543.6 & 27.9 & 580.1 & 19.0 \\
1986 & 662.3 & -4.2 & 547.1 & 0.6 & 575.9 & -0.7 \\
$1987 * \% *$ & 477.8 & -27.9 & 463.1 & -15.4 & 466.8 & -18.9 \\
$1988 * \%$ & 499.9 & 4.6 & 496.8 & 7.3 & 497.6 & 6.6 \\
\hline
\end{tabular}

FUENTES: 1973-1987 : Junta Nacional de Auxilio escolar y Becas (JUNAEB) 1988 : Mensaje Presidencial, Septiembre de 1988

* El beneficio se entrega durante 180 días del año.

$\because$ Calculada por la JUNAEB ponderando cada ración por su aporte al costo de la ración completa (Desayuno/Once: 0.25; Almuerzo: 0.75).

\#*: Considera raciones que aportan un total de sólo 700 calorías diarias.

\section{Programa de Alimentación Escolar (PAE)}

Este programa, que se encuentra a cargo de la Junta de Jardines Infantiles (JUNAEB), proporciona diariamente, y en forma gratuita, desayuno u onces (media ración) y almuerzo (ración completa), a los escolares entre 6 y 14 años matriculados en el ciclo básico de escuelas fiscales, municipales y particulares subvencionadas, procedentes de hogares en extrema pobreza. Se propone mejorar el estado nutricional de los estudiantes, así como contribuir a resolver los problemas de repitencia, ausentismo, deserción y fracaso escolar.

La ración completa proporcionaba hasta 1986, 800 calorías diarias, que cubrían un tercio de las necesidades calórico-proteicas estipuladas por las recomendaciones de la FAO-OMS para este grupo de edad, y la recibían prioritariamente quienes presentaban déficit nutricional. La media ración, en 
cambio, - que hasta ese año cubría sólo un $13 \%$ de lo recomendado por la FAO-OMS - se entrega a quienes no tienen un estado nutricional comprometido ${ }^{11}$.

En lo que se refiere a la cobertura de este programa, se calcula que en 1986 habia un mínimo de 900 mil escolares en extrema pobreza, lo que significa que ese año el PAE habría dado atención al $70 \%$ de su población-objetivo.

En 1985, el 60\% de los recursos comprometidos en el programa se focalizó en los hogares situados en los tres deciles de menores ingresos, en tanto que los hogares ubicados en los tres deciles de más altas rentas captaron sólo el $8 \%$ de esos desembolsos. Estas cifras ponen de manifiesto una considerable selectividad, la más alta de todos los programas educacionales.

\section{Programas dirigidos hacia la extrema pobreza habitacional}

El gobierno militar ha puesto en práctica un complejo sistema de subsidios habitacionales, muchos de los cuales han favorecido casi exclusivamente a los estratos medios. Aquí examinaremos sólo los subsidios focalizados específicamente en la pobreza crítica: el programa de Lotes con Infraestructura Sanitaria y el Subsidio de Marginalidad Habitacional (SMH).

\section{Lotes con Infraestructura Sanitaria}

Este programa, que se inicia en 1982, entrega soluciones conocidas bajo el nombre de "casetas sanitarias" y está destinado a resolver en forma masiva las necesidades de los sectores que viven en condiciones de extrema marginalidad habitacional, en particular, residentes de campamentos u otros asentamientos precarios. Contempla la regularización legal del terreno (títulos de dominio) en el caso de las radicaciones, y la construcción de una infraestructura sanitaria compuesta por baño, lavadero y cocina, con una superficie no inferior a $6 \mathrm{~m}^{2}$, ni superior a $8 \mathrm{~m}^{2}$ emplazada en terreno urbanizado de 100 a $160 \mathrm{~m}^{2}$.

Las soluciones son asignadas directamente entre las familias de campamentos erradicados o que son radicados en el mismo terreno que ocupaban. Se esperaba que los beneficiarios, con ayuda de programas municipales especiales - que nunca se implementaron-, realizaran en torno a la infraestructura sanitaria un esfuerzo de autoconstrucción de una vivienda definitiva.

11. A partir de 1987 se redujo el aporte energético del programa, con lo cual la ración completa pasó a suministrar solamente 700 calorías diarias. 
«Papers»: Revista de Sociologia

\section{Cuadro 4}

Soluciones habitacionales acogidas a subsidios de marginalidad habitacional, 1978-1986

\begin{tabular}{|c|c|c|c|c|c|}
\hline \multirow[b]{2}{*}{ Año } & \multicolumn{3}{|c|}{ Viviendas } & \multirow{2}{*}{$\begin{array}{c}\text { Casetas } \\
\text { sanitarias }\end{array}$} & \multirow{2}{*}{$\begin{array}{c}\text { Total } \\
\text { soluciones }\end{array}$} \\
\hline & Sociales" & Básicas"* & Totales & & \\
\hline 1978 & 22.176 & - & 22.176 & - & 22.176 \\
\hline 1979 & 15.651 & - & 15.651 & - & 15.651 \\
\hline 1980 & 11.317 & 4.909 & 16.226 & - & 16.226 \\
\hline 1981 & 6.836 & 8.942 & 15.778 & - & 15.778 \\
\hline 1982 & - & 12.599 & 12.599 & 3.484 & 16.083 \\
\hline 1983 & - & 13.489 & 13.489 & 1.343 & 14.832 \\
\hline 1984 & - & 20.410 & 20.418 & 8.558 & 28.976 \\
\hline 1985 & - & 23.112 & 23.112 & 8.877 & 31.989 \\
\hline 1986 & - & 21.749 & 21.749 & 11.121 & 32.870 \\
\hline Total & 55.980 & 105.210 & 161.198 & 33.383 & 194.581 \\
\hline
\end{tabular}

FUENTES: MINVU, Memorias Anuales y Boletines Estadisticos; Mensaje Presidencial, 1987; Puga (1986)

* Incluye viviendas realizadas por Cooperativas (mediante créditos de la AID) y viviendas de emergencia.

$\because$ Incluye viviendas económicas construidas por municipalidades.

El valor inicial de estas soluciones puede alcanzar un valor máximo de 110 UF, cuando contempla tanto la edificación como el terreno y la urbanización. No obstante, en la práctica, entre 1982 y 1985 su costo promedio osciló entre 83 y 89 UF (Haindl y Weber, 1986).

Durante los cuatro primeros años de vigencia del programa se construyeron 33,4 mil «casetas sanitarias» y su tamaño promedio fluctuó entre los 6 y $7 \mathrm{~m}^{2}$ (Cuadro 4).

\section{Subsidio de Marginalidad Habitacional (SMH)}

Creado en 1984, al año siguiente este subsidio pasa a sustituir a todas las anteriores líneas para la adquisición de una vivienda popular. Está orientado básicamente hacia aquellos hogares urbanos sumidos en extrema pobreza que no pueden ser radicados en el mismo terreno que ocupan, como es el caso de los allegados y los habitantes de "cités" y conventillos. 
Las soluciones entregadas mediante este nuevo sistema tienen una superficie máxima de $32 \mathrm{~m}^{2}$. El subsidio cubre hasta un $75 \%$ del valor de la misma, con un tope de 180 UF, y el propio SERVIU se encarga de otorgar a los asignatarios un crédito, a 20 años plazo, para cubrir la diferencia que queda entre el subsidio y el ahorro previo y el valor total de la vivienda.

A diferencia de los programas habitacionales aplicados con anterioridad, el SMH se adjudica de acuerdo a un sistema de postulación individual. Para postular al beneficio, se deben cumplir varios requisitos. Entre ellos, haber acumulado un ahorro previo. La asignación de los subsidios se realiza en función de un sistema de puntuación, en el que se pondera el índice CAS del postulante, el número de cargas familiares y su capacidad de ahorro, definida según el monto y antigüedad de sus depósitos.

En 1986 fueron asignadas aproximadamente veintidós mil viviendas acogidas a este beneficio, lo que representa un $39 \%$ del total de soluciones acogidas a algún sistema de subsidio habitacional.

La insuficiencia de las soluciones entregadas por estos programas queda de manifiesto si se recuerda que en 1980 el déficit de viviendas en Chile fluctuaba, según la estimación más conservadora disponible, entre 750 y 850 mil habitaciones (Cámara Chilena de la Construcción, 1982), sin considerar el grave problema de los allegados ni las viviendas en malas condiciones. De tomarse en cuenta esto, a mediados de la década el déficit habría ascendido a un millón cien mil viviendas y afectaría a un 36\% de las familias del país (MacDonnald, 1986) ${ }^{12}$. Sólo para congelar el déficit, según la primera estimación, habría sido necesario que durante la década del 80 se construyeran un mínimo de ochenta mil unidades habitacionales al año (Figuerola y Lavados, 1983). Pues bien, entre 1980 y 1986, el sector público entregó un promedio anual de sólo treinta y cinco mil soluciones sujetas a algún sistema de subsidios de marginalidad habitacional, incluidas las "casetas sanitarias». Si a esas cifras se agrega la construcción privada de esos mismos años, se llega a un total de cuarenta y nueve mil cien nuevas viviendas anuales. Estos solos antecedentes sirven para dejar en evidencia las limitaciones del esfuerzo que el Estado ha desplegado para encarar el problema habitacional.

La selectividad de los dos programas reseñados es alta. A fines de 1985, el $43 \%$ del gasto en viviendas básicas y "casetas sanitarias» fue asignado entre el $30 \%$ de los hogares de más bajos ingresos. No obstante, más de la mitad de los desembolsos en estos subsidios se filtraba hacia grupos de ingresos medios y altos, lo que sin duda obedece al peso que en el sistema de selección se otorga a la capacidad de ahorro del postulante.

12. Como producto de ello, al finalizar la década el déficit habitacional se había elevado a 1 millón y medio de viviendas. 


\section{Atención de salud gratuita a indigentes y personas de escasos recursos}

A diferencia de los programas antes analizados, la atención de salud que los establecimientos estatales brindan en forma gratuita a las personas en extrema pobreza no constituye, en rigor, una intervención selectiva independiente del conjunto de prestaciones que proporciona la salud pública, que tiene cobertura prácticamente universal. Se trata, más bien, de un derecho que se confiere selectivamente a quienes no cuentan con recursos suficientes para procurarse con sus propios medios los servicios médicos que requieren.

A partir de 1979 el gobierno militar impulsa una serie de reformas tendientes a reestructurar el sistema de salud estatal, con el propósito de minimizar la presencia estatal en el sector y promover el fortalecimiento de la medicina privada. En 1985 se promulga la denominada Nueva Ley de Salud, que representa la culminación de ese proceso de privatización y «mercantilización» de la salud. Ésta creó un nuevo Régimen de Prestaciones de Salud que desliga el acceso a la atención médica de la situación previsional de la persona, vinculándolo en cambio a sus ingresos. A efectos de determinar el derecho a gratuidad o el porcentaje del valor de las prestaciones que debe ser financiado por los usuarios, éstos son clasificados en cuatro categorías, de acuerdo al monto de sus ingresos: tienen derecho a recibir asistencia médica sin costo alguno en la red de salud pública quienes queden clasificados en las dos primeras categorías, que corresponden a personas indigentes y carentes de recursos; es decir, a quienes percibian hasta fines de 1989 un ingreso mensual no superior a 16.300 pesos al mes ( 94 dólares) ${ }^{13}$.

La determinación de los indigentes era hecha con anterioridad por las asistentes sociales de los propios servicios de salud, previa encuesta y visita domiciliaria. La Nueva Ley, en cambio, entrega esa labor a las municipalidades, que no disponen de información sobre ingresos, que es el criterio que esta ley establece para estos efectos. De ahí que, en la práctica, los funcionarios municipales se vieran obligados a clasificar como indigentes o personas

13. Quienes percibían hasta 1989 un ingreso entre ese valor y 25.500 pesos, debían cancelar el $25 \%$ del valor arancelario de las prestaciones, y quienes ganaban más de ese valor debían pagar el $50 \%$ de dicho arancel.

Desde que se dictó la Nueva Ley hasta fines de 1989, el monto máximo de los ingresos que permitía quedar exento del pago por las prestaciones se mantuvo congelado, reajustándose por primera vez a comienzos del presente año (1990) y en apenas un 16,9\%; es decir, a una tasa muy inferior a la inflación de ese período. Esto hizo que el valor real de ese ingreso fuera disminuyendo en forma progresiva, lo que produjo el desplazamiento automático de parte considerable de los usuarios de bajos ingresos hacia los tramos superiores, perdiendo así éstos el derecho a gratuidad. La medida creó además nuevos incentivos al traslado de los usuarios del SNSS de mayores ingresos hacia el sistema privado. 
carentes de recursos a quienes se ubica en los índices inferiores de la Ficha CAS. Esto ha generado irregularidades e ineficiencias de toda índole que han resentido severamente el acceso de los más pobres a la gratuidad médica.

Si bien con la Nueva Ley de Salud las personas afectadas por situaciones de pobreza aguda conservan el derecho a gratuidad en el SNSS, no hay que olvidar que tanto la calidad como el volumen de prestaciones que éste proporciona se han deteriorado progresivamente, a consecuencia del efecto devastador que, tanto la reducción del gasto público como el proceso de privatización tuvieron sobre el sector.

El beneficio a que tienen derecho quienes carecen de medios para procurarse una atención particular consiste en el acceso, sin costo alguno, a todas las prestaciones médicas que entrega el SNSS: atenciones preventivas, curativas, hospitalizaciones, medicamentos. Pero el derecho está limitado por los hechos: la propia Ley y su Reglamento establecen que el número de atenciones que se brinden estará determinada por los recursos de personal y equipos con que cuenten los servicios estatales. Es entonces la capacidad de atención del sistema, y no las necesidades de los usuarios o los derechos que le confiere la ley, la que determina la cantidad y calidad de las prestaciones que éstos pueden recibir.

Se entiende entonces que el déficit de atenciones del sistema de salud pública sea muy elevado: en 1985, las consultas externas proporcionadas por el SNSS a los beneficiarios potenciales de la gratuidad cubrieron estimativamente sólo el $45 \%$ de las necesidades mínimas de quienes carecen de medios para costearse una atención particular (Vergara, 1989).

\section{APRECIACIÓN CRÍTICA DE LOS PROGRAMAS}

En esta sección nos interesa destacar algunos de los resultados más sobresalientes de la experiencia chilena reciente en la aplicación de programas focalizados en la extrema pobreza, y extraer las principales lecciones que ellos entregan para la generación de soluciones alternativas de mayor efectividad e impacto, susceptibles de ser aplicadas por el futuro gobierno democrático.

\section{Cobertura y selectividad de los subsidios}

Una primera conclusión que fluye del análisis de los programas hacia la pobreza crítica se relaciona con la escasa magnitud de los recursos que se les destinan: durante los últimos años, no han movilizado más de un $15 \%$ de un gasto social que, en términos reales, ha experimentado durante la última década una severa contracción (Cabezas, 1988). 
«Papers»: Revista de Sociologia

En el área previsional, por ejemplo, los fondos destinados al SUF han representado apenas el $3 \%$ del aporte fiscal a la seguridad social, en tanto que al pago de las pensiones asistenciales se ha canalizado menos del $5 \%$ del gasto en el sector. Por su parte, hasta 1988, el aporte fiscal a la JUNJI no superaba el $2 \%$ de los desembolsos en educación. El gasto en el PAE ha sido igualmente insuficiente, como lo ha sido también en las demás acciones emprendidas para erradicar la pobreza. No es extraño entonces que la cobertura de sus respectivos grupos focales sea limitada, y que el monto de los beneficios sea también muy insuficiente en relación a la magnitud creciente de los problemas sociales que se enfrentan.

En materia de selectividad, en cambio, no cabe duda que se han logrado avances notables con respecto a los que exhibían las políticas sociales hasta mediados de los años setenta. Es cierto que esos progresos son claramente insuficientes: en promedio, sólo algo más de la mitad del gasto público movilizado por estos subsidios se focaliza en los hogares más necesitados. Sin embargo, no hay que olvidar que se trata de grupos que antes se encontraban marginados por completo de los beneficios sociales que otorga el Estado.

\section{Eficacia de los mecanismos de selección y asignación de subsidios}

Es evidente que la validez y confiabilidad de los mecanismos de detección de grupos focales constituye un factor crucial del éxito de cualquier intervención selectiva. Las experiencias examinadas demuestran, en efecto, que las deficiencias del instrumento utilizado para identificar y priorizar a los beneficiarios potenciales de los subsidios - la Ficha CAS - constituye una de las principales limitantes de su selectividad.

Sus fallas obedecen, en primer término, a la ausencia de un marco conceptual en su construcción que fundamente la selección de los indicadores y la ponderación acordada a cada uno de ellos. Derivan también del uso, no obstante el carácter heterogéneo y multifacético de la pobreza, de un índice sintético global para delimitar grupos focales y asignar subsidios que buscan encarar vulnerabilidades también muy específicas y diversas. En la práctica se traduce en la exclusión de los hogares que exhiben carencias agudas en algunas dimensiones, pero que los valores alcanzados en otros indicadores hace que no queden clasificados como pobres críticos. Además, ese índice varía dentro de un rango excesivamente estrecho, lo que le confiere escasa aptitud discriminatoria. Por otro lado, la utilización de un instrumento único y uniforme para medir niveles de deprivación y detectar grupos focales a lo largo de todo el país impide la generación de soluciones que se adecúen a las especifidades locales. 
No obstante, las limitaciones de fondo de la Ficha CAS derivan de su propia naturaleza y del sistema de apoyo individual a que ella apunta. Tal vez una de las más graves estribe en la pretensión de estructurar con ella un sistema de información social para delimitar grupos focales a partir de datos individuales, lo que envuelve la asignación también individual de subsidios a postulantes aislados, a los que se comprueba que son víctimas de grados muy altos de vulnerabilidad. En otras palabras, los pobres son tratados como meros agregados estadísticos, aplicables a cualquier contexto, no considerándose en absoluto sus diferentes modalidades de inserción en la estructura económica y social y en el mundo cultural en el cual se desenvuelven, así como tampoco los factores específicos que en cada caso particular condicionan su acceso a los servicios sociales.

La sustitución del Índice CAS por indicadores de ingreso tampoco constituye una solución satisfactoria. Aparte de compartir muchas de sus limitaciones, las dificultades de orden práctico que suscita su utilización para efectos de la selección de beneficiarios no son de menor envergadura. Así, por ejemplo, la necesidad de acreditar mediante documentación formal un ingreso mínimo para acceder al Subsidio de Marginalidad Habitacional -y también al préstamo hipotecario complementario requerido para financiar el valor de la vivienda no cubierto por el subsidio- margina automáticamente del programa a la inmensa mayoría de los segmentos más pobres de la población, a quienes les resulta extremadamente difícil acreditar sus ingresos, debido a que no son asalariados, sino cesantes, trabajadores ocasionales o por cuenta propia, o se desempeñan en trabajos informales.

Pero mucho más difícil todavía es probar documentalmente la indigencia; es decir, certificar que se carece de ingresos o que los que se perciben son insuficientes para subsistir, como se exige para acceder a una pensión asistencial o para gozar de gratuidad absoluta en los servicios públicos de salud.

El problema es extremadamente complejo y no existen hasta el momento respuestas satisfactorias. En todo caso, parece imprescindible combinar los sistemas de postulación y asignación individual para algunos subsidios -los previsionales, por ejemplo-, con otros mecanismos e instrumentos que redefinan la unidad de intervención. Dependiendo de la naturaleza del programa, éstas pueden estar representadas por áreas territoriales donde las condiciones de vida son especialmente deficitarias (campamentos, por ejemplo), por organizaciones productivas precarias o informales (talleres laborales, cooperativas), o por diferentes combinaciones de ellas.

En todo caso, los métodos utilizados en el pasado para determinar quienes tenían acceso gratuito a ciertos servicios - que se basaban en una entrevista, seguida de una visita domiciliaria de las asistentes sociales de los organismos públicos respectivos-, aunque mucho más pragmáticos y flexi- 
«Papers»: Revista de Sociologia

bles, eran con seguridad más simples y no menos efectivos que los confusos y costosos procedimientos adoptados en la actualidad.

\section{Riesgos y efectos negativos de la focalización de los subsidios}

Los programas analizados comprueban que no existen recetas mágicas ni fórmulas únicas para responder al desafío de erradicar definitivamente la pobreza, y que no siempre la focalización de los beneficios sociales es el camino más adecuado, pudiendo en ocasiones suscitar incluso efectos contraproducentes.

Es cierto que nadie podría negar la urgencia de aliviar las necesidades sociales más apremiantes, por lo que los avances en esa dirección constituyen un objetivo que no puede ser dejado de lado. Pero ello no significa que puedan abandonarse las políticas sociales tradicionales, de cobertura universal, ni reducir de manera apreciable los recursos que se les destinan para canalizarlos hacia acciones focalizadas en los grupos más vulnerables, sobre todo si se tiene en cuenta que el gasto social es ya demasiado exiguo en relación a la magnitud $\mathrm{e}$ intensidad de las necesidades insatisfechas.

Más aún, los instrumentos tradicionales no pueden ser excluidos de ninguna estrategia de erradicación de la pobreza ${ }^{14}$. No hay que olvidar que la "línea de pobreza» trazada para delimitar los hogares que no alcanzan niveles mínimos de bienestar tiene fronteras muy fluidas, más aún si se recuerda que ese umbral crítico fue determinado mediante simples procedimientos técnico-estadísticos que no necesariamente dan cuenta de la intensidad del problema. De suspenderse la ayuda que entrega el Estado a través de esas políticas, con seguridad parte no despreciable de sus actuales beneficiarios incurrirían en déficits en sus necesidades esenciales, pasando así a engrosar las filas de la pobreza crítica. En consecuencia, la conveniencia de adoptar esa medida -especialmente en lo que se refiere a sus efectos sobre aquellos grupos que se sitúan apenas por encima del umbral mínimo de bienestar - debe ser en cada caso debidamente evaluada, así como también las condiciones bajo las cuales cabe esperar resultados exitosos (Sojo, 1989; CEPAL, 1987).

De ahí que, si no se desea acarrear una pauperización de esa población intermedia -como de hecho ha ocurrido durante los últimos 15 años con

14. Si bien históricamente estas políticas han servido para inducir el progreso en las condiciones de vida de los trabajadores asalariados, benefician también a una parte apreciable de los grupos más pobres debido a que el fenómeno afecta a grandes contingentes de empleados y obreros de empresas grandes y medianas, y éstos quedan excluidos de los programas focalizados en la extrema pobreza. Véase Cortázar (1977); Vergara (1978); Pollack y Uthoff (1986). 
parte considerable de los sectores medios- y asegurar que la selectividad tenga efectos positivos sobre las condiciones de vida de la población, esos esfuerzos deben verse acompañados de una expansión significativa del presupuesto que se destina a los programas, de tal modo que la medida sea financiada con recursos adicionales, y no mediante una reducción de la cobertura del programa y/o de la calidad del beneficio que se proporciona.

El PNAC es una evidente comprobación de lo que decimos: al no provenir el intento de promover su selectividad de un incremento, sino de una marcada reducción de los fondos que se le destinan, ese objetivo se consiguió canalizando la mayor parte de la ayuda hacia los grupos más vulnerables, en desmedro del subsidio alimentario que se otorga a los usuarios que no enfrentan riesgo. Con ello, se desestimuló la participación de estos últimos en el programa, lo que erosionó severamente su impacto y comprometió la continuidad de las acciones de fomento y prevención de la salud asociadas a la entrega de alimentos. Se arriesgaron así los meritorios logros del programa en la reducción de las tasas de mortalidad y desnutrición infantiles, en la medida que muchos niños que no estaban amenazados por este mal pasen a vivir en una situación de alto riesgo y terminen presentando desnutrición. Por otro lado, la medida terminó por sustituir progresivamente los propósitos preventivos del programa por una finalidad netamente curativa: eliminar el daño nutricional una vez que éste ya se ha presentado ${ }^{15}$.

No debe olvidarse, por otra parte, que los esfuerzos por imprimir una mayor selectividad al gasto - con mayor razón aún si no se dispone de financiamiento adicional-, deben descansar fundamentalmente en el uso de mecanismos directos o indirectos que reduzcan el porcentaje de éste que llega a los grupos de mayores recursos. Un buen ejemplo de ello son las exigencias que promueven la autoexclusión de esos sectores del reparto de leche.

En esa misma línea, debiera explorarse la posibilidad de lograr avances en materia de selectividad, haciendo extensivo ese criterio al tipo de bienes y servicios que proveen los programas, lo que se puede lograr ya sea reduciendo la oferta de las prestaciones de más alto costo para incrementar las de menor costo relativo - privilegiando los programas de salud preventiva

15. En menor medida, esto mismo ha sucedido en el caso del PAE y del programa de la JUNJI. Aparte de incrementar sustancialmente los costos, el mayor énfasis otorgado a los menores que presentan un estado nutricional comprometido desvirtuó las finalidades para las cuales estas intervenciones habían sido creadas y deterioró su alcance y su efectividad, sin que tampoco se hayan logrado progresos sustanciales en el propósito de combatir la desnutrición. 
y la asistencia médica de las patologías típicas de la población más pobre, por encima de la medicina curativa, por ejemplo-, o mediante una selección adecuada de los bienes y servicios que se otorgan, escogiendo cuidadosamente aquéllos que sean concordantes con las necesidades, preferencias y carencias específicas de los grupos más desposeídos y que, a la vez, no resulten necesarios o atractivos para los sectores de mayores ingresos.

Ciertamente que estos problemas sitúan en el marco real pertinente la evaluación de los avances en materia de focalización del gasto social en los más pobres. Sin perjuicio de la conveniencia de lograr esa meta, debe comprenderse que, en la lucha contra la miseria y la marginalidad social, el factor crucial lo constituye la magnitud de los fondos que se destinen a ese objetivo, y que no se lograrán progresos apreciables en esa dirección sólo mediante propuestas de focalización. Pero tampoco debe plantearse esa meta en términos simplificados, como una disyuntiva entre políticas selectivas vs. universales. El diseño de una política social equitativa admite múltiples opciones, por lo que ella debe contemplar orientaciones tanto selectivas como universalistas, evaluando debidamente en cada caso la pertinencia de una u otra alternativa, o de alguna de sus múltiples posibles combinaciones.

No obstante, desde una perspectiva de más largo plazo, el mayor peligro que involucran las propuestas de focalización y privatización de los servicios sociales es su tendencia a reforzar el dualismo que caracteriza a la institucionalidad social impuesta por el neoliberalismo; vale decir, modernización para unos pocos a expensas de la exclusión y dependencia perpetua del asistencialismo estatal de la mayoría, contribuyendo de ese modo a acentuar las repercusiones sociales adversas del modelo económico, y a consolidar la fragmentación y dualización de la estructura social chilena.

Esta situación plantea serios desafíos al futuro gobierno democrático. Dada la extensión e intensidad que ha alcanzado la pobreza y la marginalidad social, y el marco de severas restricciones de la más diversa índole que deberá enfrentar, no será posible en breve plazo satisfacer las enormes carencias acumuladas. Resultará indispensable, en consecuencia, combinar programas de emergencia que aseguren una protección asistencial mínima a los más pobres, con soluciones más permanentes, que abarquen al conjunto de la población. Pero no existen recetas mágicas ni fórmulas únicas para conciliar ambas orientaciones sin que ello redunde en el afianzamiento y perpetuación de los sistemas duales y segmentados a que se ha hecho alusión.

Con todo, es preciso tener presente que una estrategia efectiva de erradicación de la pobreza crítica sólo puede tener efectos duraderos si la provisión directa de bienes y servicios por parte del Estado se ve acompañada de un 
esfuerzo por mejorar en forma permanente las condiciones de productividad y empleo, y por lo tanto, la capacidad de generar ingresos de los grupos más desposeídos. De otro modo, no será posible compatibilizar el crecimiento de la economía con una mayor equidad en la distribución de los frutos del desarrollo.

\section{Reestructuración y descentralización de la prestación de servicios básicos}

A la luz de las experiencias examinadas, resalta el hecho de que para terminar con las situaciones de necesidad más apremiantes, el incremento del gasto social y la reorientación del mismo tendiente a imprimirle mayor selectividad son indispensables, pero totalmente insuficientes. Para enfrentar los problemas sociales en su real magnitud, especialmente cuando se trata de poner en marcha acciones selectivas que requieren de instrumentos y modalidades de operación mucho más complejas, esos esfuerzos requieren de una modificación profunda de las estructuras administrativas del estado y de la actual organización de los servicios sociales en orden a superar sus principales ineficiencias y rigideces. Junto con desburocratizar el aparato estatal y permitir una conducción unificada de la política social y de ésta con la política económica, esas reformas facilitarían la coórdinación entre instituciones y programas. Pero esos objetivos no llegarán muy lejos en la meta de superar las formas más extremas de pobreza si no contemplan una efectiva descentralización y democratización de la política social que abra espacios de participación de la población en las distintas instancias y niveles de decisión estatal.

Es cierto que la idea de la descentralización ha cobrado últimamente gran fuerza. En esa línea, el actual gobierno ha promovido la administración descentralizada de algunos servicios básicos (educación pre-básica y básica, atención de salud primaria, entre otros), y de los programas que conforman la red social, si bien se sostiene que deben ser diseñados y coordinados a nivel central. Pero, aunque se ha hecho bastante caudal en torno a que supuestamente el diseño centralizado de estas intervenciones va de la mano con una gestión descentralizada, lo cierto es que esa combinación no ha llegado a darse en la práctica. Tanto el diseño como las modalidades de ejecución de los programas - sus instrumentos y normas concretas de aplicación, los criterios de selección de beneficiarios, los beneficios y los aspectos técnico-administrativos- son rígidamente predeterminados en los niveles centrales del estado, sin que tampoco ello se haya traducido en una acertada coordinación entre instituciones y programas. La centralización e inflexibilidad de los programas es tan considerable que los municipios, en los cuales recae supuestamente la tarea de ponerlos en marcha, práctica- 
mente no tienen margen de maniobra alguno para realizar siquiera pequeños ajustes, a fin de focalizar mejor los subsidios en las personas más necesitadas y adaptar las acciones a las necesidades específicas de cada grupo y localidad.

El PAE muestra muy nítidamente los extremos a que ha llegado la centralización en el manejo de los programas hacia la extrema pobreza actualmente en curso, y las graves ineficiencias que ello trae consigo. Éstas quedaron en evidencia, por ejemplo, en los intentos de la JUNAEB de llevar a cabo, en sus oficinas centrales, la selección definitiva de los beneficiarios de cada una de las raciones que suministra ese programa en las miles de escuelas del país.

No es extraña entonces la ausencia de coherencia que se advierte entre los programas y la descoordinación que existe entre las instituciones bajo las cuales éstos se implementan, como tampoco la absoluta ausencia de una jerarquía de prioridades en el volumen de fondos que el Estado destina a cada uno de ellos. Tampoco sorprende que ello haya redundado en una fuerte erosión de la eficiencia e impacto potencial de las acciones que se emprenden, como asimismo de la política social en su conjunto. El actual régimen ha llegado a la peor de las combinaciones: una centralización extrema tanto en el diseño como en la definición de las modalidades de ejecución de los programas, sin que se haya logrado tampoco una efectiva coordinación central.

\section{Rol del mercado y del estado}

Tan importante como el reordenamiento institucional de los servicios al interior del aparato estatal, es la redefinición del papel que éste debe jugar en la política social y, en particular, en la estrategia de erradicación de la extrema pobreza.

La experiencia chilena reciente en esta materia ha dejado en evidencia que el mercado, operando libremente, no constituye el mecanismo más idóneo para regular la producción de los bienes y servicios que otorga la política social, y que la reducción de la presencia estatal en este campo ha tenido repercusiones sociales adversas que superan por amplio margen la capacidad que puedan tener programas meramente paliativos y compensadores de superar las situaciones de pobreza más aguda, al menos dentro de un horizonte éticamente aceptable de tiempo. La satisfacción de las necesidades básicas de toda la población exige que el estado, como representante de los intereses generales de la nación, amplíe sustancialmente su rol dirigente en la gestión del desarrollo y en la conducción de la política social, de modo que esté en condiciones de definir políticas globales y sectoriales que le permitan 
incrementar significativamente los recursos destinados a fines sociales, y reorientarlos progresivamente hacia programas que alivien las carencias acumuladas ${ }^{16}$.

En primer lugar, al entregarse la producción de bienes y servicios esenciales a empresas privadas sujetas a muy pocas regulaciones, ésta queda determinada básicamente por consideraciones de costo y maximización de utilidades, y no en función de las reales necesidades de los destinatarios. Esto ha suscitado fuertes incongruencias en algunos programas: con frecuencia, los beneficios que ellos proveen no atienden a las costumbres y prácticas de quienes viven la extrema pobreza, ni a la racionalidad que caracteriza su comportamiento frente a la satisfacción de sus necesidades básicas, lo que hace que sean rechazados por sus destinatarios. Algunos de los subsidios alimentarios que otorga el PAE, por ejemplo - cuya producción es encargada a firmas privadas-, no son valorados por los usuarios, e incluso muchas veces entran en abierto conflicto con la cultura alimentaria de los grupos pobres. Un problema similar se genera en los programas de marginalidad habitacional: las viviendas económicas que pueden ser adquiridas en el mercado con los subsidios son a menudo construidas más de acuerdo con los estilos de vida y preferencias de los estratos medios que en función de las necesidades de sus presuntos ocupantes. Además, para abaratar costos, se emplean materiales de mala calidad y las viviendas se emplazan en áreas distantes - y por lo general extremadamente precarias-, donde los terrenos son más baratos, pese a lo cual resultan más caras que las que son contratadas o construidas directamente por las agencias estatales y luego asignadas a los hogares beneficiados (Arellano, 1985).

Por otra parte, el exiguo poder adquisitivo de estos sectores no gravita en el mercado, aun cuando se encuentre subsidiado, por lo que, si la concesión de subsidios directos no se ve acompañada de una intervención directa del estado tendiente a asegurar una oferta adecuada de bienes y servicios susceptibles de ser adquiridos con ellos, parte considerable de los beneficiarios no podrán hacer uso del beneficio una vez que les es asignado. La experiencia de algunas líneas de subsidio habitacional que rigieron entre 1980 y 1985 ilustran en forma elocuente esta situación: parte considerable de los subsidios que esos programas otorgaron quedaron sin utilizar o fueron a parar a familias más acomodadas (Tagle, 1982).

El rígido verticalismo con que son diseñados y gestionados los programas agrava aún más el problema, en la medida que impide la generación de solu-

16. Es evidente que uno de los primeros pasos que debieran darse en esa dirección es la reasignación de los recursos que se destina a los gastos militares, los cuales actualmente ocupan una porción significativa del gasto público. 
ciones que se adecúen mejor a las características socio-culturales y conductas específicas de los grupos más vulnerables que existen en las diferentes áreas territoriales del país.

Pero como se viera, en algunos programas los principios mercantiles se introducen también en la regulación del acceso a los subsidios, como ocurre, por ejemplo, cuando se vincula el derecho al beneficio a la capacidad de ahorro de los potenciales beneficiarios. Es el caso típico del Subsidio de Marginalidad Habitacional: al otorgarse al monto y antigüedad de los depósitos un peso decisivo en la puntuación para acceder al subsidio, se hace competir a los postulantes entre sí en función del monto del ahorro que logran acumular, competencia en la cual lógicamente los sectores más desposeídos se ven desplazados por los postulantes de mayores recursos.

Cabe subrayar que una mayor intervención del Estado que le permita asumir una posición de liderazgo en la política social no supone necesariamente aumentar el tamaño del aparato público, ni imponer restricciones burocráticas indiscriminadas, así como tampoco la estatización de los servicios sociales. Por el contrario, se trata de proveerlo de la capacidad política y técnica necesaria para definir las orientaciones fundamentales de la estrategia de desarrollo social y encauzarla de acuerdo a sus criterios propios y prioridades. Pero el logro de ese objetivo da cabida a múltiples opciones de organización de los servicios públicos, y es compatible con diversos grados de descentralización político-administrativa y con diversas combinaciones de participación de los sectores público, privado y comunitario en la materialización de la política social.

\section{La participación de los beneficiarios}

Otra conclusión que fluye del análisis de estos programas es que muchas de sus limitaciones e ineficiencias podrían haberse evitado o aminorado si la comunidad, y en particular los hogares afectados por la pobreza, hubieran intervenido en su formulación, ejecución y control. Por ejemplo, en la definición de sus necesidades más urgentes, en la selección de los bienes y servicios que requieren, en la identificación de las personas que requieren atención prioritaria, así como también en la ejecución misma del programa. Además de contribuir a elevar la selectividad e impacto de estas intervenciones y a desburocratizar la prestación de servicios sociales, esa participación permite movilizar las energías y los recursos potenciales de la comunidad en la consecución de las metas sociales.

Algunas experiencias gubernamentales recientes - aunque incipientes y escasas- ponen de manifiesto las enormes potencialidades que encierra la colaboración de los destinatarios en la ejecución de tareas simples pero 
imprescindibles al interior del respectivo programa. Es el caso de los programas experimentales desarrollados por la JUNJI y de algunos proyectos municipales de recuperación de desnutridos, que son atendidos por madres previamente capacitadas. Los subsidios de marginalidad habitacional, en cambio, constituyen uno de los mejores ejemplos de las deficiencias y omisiones en que han incurrido los programas en este sentido: en ellos el único esfuerzo que se solicita a los postulantes es la acumulación de un ahorro previo, en circunstancias en que eso es precisamente lo que a éstos más les cuesta entregar. Se desperdicia en cambio el aporte de su mano de obra a la construcción de su propia vivienda, a pesar de que los pobladores chilenos han demostrado siempre una gran capacidad de autoconstrucción (MacDonnald, 1983) ${ }^{17}$.

Por otra parte, la exigencia al beneficiario o a su grupo familiar de aportar su esfuerzo y capacidades a la solución de sus problemas atenuaría el carácter netamente asistencialista de estos subsidios, que ha terminado generando en sus beneficiarios una actitud de conformismo y pasividad respecto de la superación de la pobreza que los aflige, y una dependencia crónica de los subsidios estatales. Al mismo tiempo, ese requisito puede constituirse en un mecanismo indirecto de focalización, al promover la autoexclusión de las personas menos necesitadas.

Pero esa participación no puede limitarse a la materialización de programas específicos. La viabilidad política y el éxito de una estrategia eficaz de satisfacción de las necesidades básicas está indisolublemente ligada a una efectiva democratización de la política social en dos niveles. Por un lado, se requiere que el sistema político dé cabida a la participación activa de todas las fuerzas sociales, a través de sus representantes en el Parlamento, en las grandes decisiones relacionadas con la formulación, ejecución y fiscalización de la estrategia de desarrollo social: sus principales objetivos, sus contenidos, prioridades y plazos, y la asignación de los recursos correspondientes. Si éstas no son expresión de decisiones democráticamente tomadas sino de resoluciones tecnocráticas impuestas verticalmente por la autoridad central, como ha ocurrido bajo el régimen militar, difícilmente las medidas que se adopten defenderán los intereses de las mayorías postergadas.

17. En relación al tema de la participación de los usuarios en la ejecución de los programas sociales, es imposible dejar de mencionar la experiencia de los organismos no gubernamentales (ONG) que trabajan en el ámbito poblacional, procurando paliar los efectos de la miseria, la cesantía y la marginación de los beneficios estatales que han sufrido los estratos más pobres. Sus experiencias confirman de manera irrefutable las enormes posibilidades que abre la participación activa de la comunidad en los programas sociales. 
Por otro lado, la lucha contra la pobreza requiere que también las instancias locales de decisión estén abiertas a la participación de la comunidad y sus organizaciones, y en particular de los grupos más pobres, en las decisiones relacionadas con aquellas materias que les atañen directamente, objetivo que hasta ahora tampoco se ha cumplido.

No obstante, para que la democratización de la política social pueda llevarse a cabo y sea efectiva, debe necesariamente asentarse en una efectiva descentralización de las decisiones que transfiera competencias, atribuciones y recursos desde los niveles centrales del Estado hacia las municipalidades, de modo que éstas incrementen sustancialmente su autonomía y su capacidad de decisión y gestión de la política social dentro de sus respectivos marcos de acción, y muy particularmente en las acciones orientadas a mejorar las condiciones de vida de la población más postergada ${ }^{18}$.

Con todas las complejidades, ineficiencias y obstáculos de diversa índole que ello pueda entrañar, sobre todo en sus fases iniciales, la necesaria descentralización de los servicios y programas sociales combinada con la participación democrática de la comunidad - y en particular de los grupos involucrados-en su gestación, administración y control parece indicar uno de los caminos que puede conducir a la definitiva erradicación de la extrema pobreza en Chile.

Santiago, enero de 1990.

18. Para ello, las políticas sociales del próximo gobierno deben estar acompañadas de una revitalización acelerada de las Juntas de Vecinos y de todas las instancias de participación de los sectores populares, incluidas las organizaciones no gubernamentales. La reforma municipal también se revela aquí fundamental: los Consejos de Desarrollo Comunal (CODECO) pueden ser instancias de participación si se modifica su composición y su forma de designación, de tal modo que sean representativos de todos los sectores sociales de la comuna y en especial de los más necesitados. 
La política social y los programas hacia la extrema pobreza

\section{BIBLIOGRAFÍA}

Altimir, O. (1979), «La dimensión de la pobreza en América Latina», Cuadernos de la CEPAL, Santiago.

Altimir, O. (1981), «La pobreza en América Latina. Un examen de conceptos y datos", Revista de la CEPAL, $\mathrm{n}^{\circ} 13$, abril.

Arellano, J. P. (1985), Políticas sociales y desarrollo. Chile 1924-1984. CIEPLAN.

Arellano, J. P. y M. Marfán (1987), «25 años de política fiscal en Chile», Estudios CIEPLAN, 21, junio.

Atalah, F. y otros (1986), "Salud y programas de alimentación complementarias», Vida Médica, vol. $37, \mathrm{n}^{\circ} 1$, primer trimestre.

Banco Mundial (1987a), Protección de la población pobre durante periodos de ajuste. Washington.

Banco Mundial (1987b), «El financiamiento de los servicios de salud en los paises en desarrollo. Una agenda para la reforma», Boletin de la Oficina Sanitaria Panamericana, vol. 103, $\mathrm{n}^{\circ}$ 6, Washington, diciembre.

Campero, G. y J.A. Valenzuela, (1984), El movimiento sindical en el régimen militar chileno: 1973-1981. Estudios ILET.

CEPAL (1985), La pobreza en América Latina: dimensiones y politicas. Estudios e Informes de la CEPAL, $\mathrm{n}^{\circ}$ 54, Naciones Unidas, Santiago.

Cortázar, R. (1977), «Necesidades básicas y extrema pobreza», Estudios CIEPLAN, 17, diciembre.

Ffrench-Davis, R. y D. Raczynski (1987), «The impact of global ressesion in living standars: Chile", Notas Técnicas, 97, CIEPLAN, marzo.

Figuerola, M. e I. Lavados (1983), «Elementos para un análisis económico de la vivienda popular en Chile", en MacDonnald (1983).

Foxley, A.; E. Aninat y J. P. Arellano (1980), Las desigualdades económicas y la acción social del Estado, FCE-CEPLAN, México.

García, A. y otros, «El problema alimentario y nutricional en Chile: Diagnóstico y evaluación de políticas», Monografías sobre empleo, $n^{\circ} 33$, PREALC/ISS, septiembre.

Haindl, E. y C. Weber (1986), Impacto distributivo del gasto social. Serie de Investigaciones, Departamento de Economía, Universidad de Chile.

Haramoto, E., «Políticas de vivienda social. Experiencia chilena de las tres últimas décadas», en MacDonnald (1983).

JUNJI (1986), Evaluación modalidades alternativas de atención. Informe Final, Depto. Técnico Pedagógico, mayo.

Larrain, F. (ed.) (1988), Desarrollo económico y democracia. Proposiciones para una sociedad libre y solidaria. Ediciones Universidad Católica de Chile.

MacDonnald, J. (ed.) (1983), Vivienda social. Reflexiones y experiencias. CPU.

MacDonnald, J. (1986), Diagnóstico babitacional. Serie Documentos de Trabajo CPU, $\mathrm{n}^{\circ} 13$, agosto.

Marfán, M. (1985), «El conflicto entre la recaudación de impuestos y la inversión privada: elementos para una reforma tributaria», Estudios CIEPLAN, 18, diciembre. 
«Papers»: Revista de Sociologia

ODEPLAN, Informe Social, varios años.

ODEPLAN (1984), Análisis de los principales programas sociales. Exposición al Sr. Ministro de Hacienda, (mimeo), agosto.

ODEPLAN-Instituto de Economía (1985), Mapa de la extrema pobreza. Univesidad Católica de Chile.

Pollack, M. y A. Uthoff (1986), El mercado y la extrema pobreza en Chile. PREALC, Santiago.

Pozo, H. y P. Vergara (1989), "Les politiques sociales au Chili», Amerique Latine, $\mathrm{n}^{\circ}$ 49, París.

PREALC (1986), Buscando la equidad. Planificación para la satisfacción de las necesidades básicas. OIT. Santiago.

Puga, E. (1987), Análisis de los sistemas de subsidio habitacional en el financiamiento de la vivienda para sectores de menores ingresos, Memoria de Título, Facultad de Ciencias Físicas y Matemáticas, Universidad de Chile.

Rayo, G. (1987), La politique sociale sous le régime autoritaire chilien. L'expérience néo-liberal. Thèse de Doctorat, Université des Sciences Sociales de Grenoble II, Institut d'Études Politiques.

República de Chile (1974), Lineas de acción del gobierno de Chile marzo.

Rodríguez, J. (1985), La distribución del ingreso y el gasto social en Chile, 1983. ILADES.

Tagle, J. (1982), «Subsidio habitacional y política de vivienda», Notas Técnicas $\mathrm{n}^{\circ} 51$, CIEPLAN, mayo.

Torche, A. (1985), «Pobreza extrema y gasto social: definiciones y opciones de política económica», en APSAL-ISUC: Aspectos metodológicos de las políticas de desarrollo social, Estudios ILPES/UNICEF sobre Políticas Sociales, 1985.

Torche, A. (1988), "Distribuir el ingreso para satisfacer las necesidades básicas", en Larraín (1988).

Vergara, P. (1978), «Necesidades básicas y políticas contra la pobreza: la experiencia de Chile», Estudios CIEPLAN, n²7, septiembre.

Vergara, P. (1985), Auge y caída del neoliberalismo en Chile. FLACSO: Santiago.

Vergara, P. (1989), Politicas hacia la extrema pobreza en Chile, 1973-1988. FLACSO: Santiago.

World Bank (1986), Poverty in Latin America. The Impact of Depression. A World Bank Publication, Washington, november. 